\title{
AS COMEMORAÇÕES DO TRICENTENÁRIO DE CAMÕES NO BRASIL
}

\author{
Marcelo Corrêa Sandmann*
}

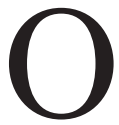

ano de 1880 irá encontrar Portugal e Brasil de alguma forma irmanados hum mesmo evento comemorativo: os trezentos anos da morte do poeta português Luís de Camões, largamente festejados aquém e além-mar.

Em Portugal, as comemorações acabariam por ser capitaneadas por Teófilo Braga, e envolveriam todo o país. ${ }^{1}$ Braga, republicano convicto, que nos anos de 1910 e 1915 iria assumir provisoriamente a presidência da recém-proclamada República Portuguesa, publicava em janeiro de 1880, no jornal Comércio de Portugal, de Lisboa, uma série de três artigos justamente intitulados " $\mathrm{O}$ Centenário de Camões em 1880". Ali, além das digressões eruditas do camoniano que era, propunha a celebração do tricentenário como uma espécie de regeneração espiritual do país. E sentenciava: "O Centenário de Camões neste momento histórico, e nesta crise dos espíritos tem a significação de uma revivescência nacional."'2

* Universidade Federal do Paraná.

1 No que diz respeito às comemorações em Portugal, um balanço dos principais protagonistas e fatos, bem como a explicitação do significado político e social do evento, paralelamente ao significado literário, podem ser encontrados no ensaio "Comemorações Camonianas de 1880", de Alexandre Cabral (CABRAL, A. Notas oitocentistas - I. Lisboa: Horizonte, 1980).

2 CABRAL, op. cit,. p. 59. 
Vivia-se então um momento de crise das instituições monárquicas em Portugal, a que se seguia o fortalecimento do Partido Republicano e reivindicações democráticas que se mostravam incompatíveis com o regime. Teófilo Braga acabaria por politizar as comemorações, transformando-as em manifestação de afirmação nacional, com evidentes colorações antimonárquicas e prórepublicanas.

Incitados pelos artigos de Braga, diversos jornalistas e intelectuais da capital portuguesa iriam se reunir nos dias 3 e 8 de abril para organizar a Comissão Executiva da Imprensa de Lisboa e eleger uma subcomissão responsável por articular as comemorações camonianas. Essa subcomissão seria sugestivamente intitulada de "Comitê de Salvação Pública", e dela fariam parte, entre outros, Teófilo Braga e o escritor Ramalho Ortigão. Seria só a partir de então que algumas importantes instituições nacionais, como a Academia das Ciências de Lisboa e a Universidade de Coimbra, além do próprio governo, iriam dar sua gradual adesão ao evento.

A agitação intelectual no país em função das comemorações seria significativa. Muitos estudos a respeito do vate português, de maior ou menor relevo, vieram a público. Alguns, inclusive, de estudiosos estrangeiros, explicitando mais uma vez o alcance da obra de Camões para além das fronteiras dos países de língua portuguesa. Produziu-se muita poesia também, em sua maioria de forte acento encomiástico e questionável valor literário.

Os festejos em Lisboa nos dias 8, 9 e 10 de junho atraíram grande público. A partir de crônica de J. Estevão de Azevedo, escrita no calor dos acontecimentos, pode-se ter uma idéia da programação para aqueles dias na capital portuguesa. ${ }^{3}$

No dia 8, efetuou-se a trasladação dos restos mortais de Luís de Camões e de Vasco da Gama para a igreja de Santa Maria de Belém, seguida de cerimônia religiosa. $\mathrm{O}$ cronista registrava com as seguintes cores o concurso popular: "Mesclavam-se todas as classes, em fraternal união. O povo, o jornalismo, a aristocracia; a nobreza dos sentimentos, do talento e do sangue." ${ }^{4}$

No dia 9, realizou-se uma sessão pública da Academia Real das Ciências, além de récitas no teatro $\mathrm{D}$. Maria, com artistas de diferentes companhias teatrais apresentando trechos de seu repertório e poemas escritos para a ocasião.

Finalmente, no dia 10 de junho, realizou-se um “cortejo cívico" pelas ruas de Lisboa. Tal cortejo, nas palavras do mesmo cronista, era "composto das várias Câmaras Municipais do reino, das escolas superiores, dos institutos oficiais e particulares, das sociedades de ciências, de comércio, de indústria, de

3 A crônica de J. Estevão de Azevedo encontra-se reproduzida em apêndice, no mesmo volume, ao final do ensaio de Alexandre Cabral.

4 CABRAL, op. cit., p. 144. 
socorros, de recreio" e deveria sair da Praça do Comércio, correr as ruas da Baixa e passar, por fim, em homenagem diante da estátua de Luís de Camões, "onde seriam depostas as coroas e as flores, que desejassem oferecer, como prova de respeito e de reconhecimento, ao ilustre cantor das nossas glórias pátrias."

Relevando um pouco o entusiasmo do cronista e sua percepção de uma fraternidade portuguesa que pairaria acima das tensões sociais daquele momento, parece claro, de qualquer forma, o fato de que o nome de Camões pôde congregar diferentes segmentos da sociedade e concentrar sobre si fortes desejos de afirmação nacional, num apelo que extrapolou certamente o interesse dos grupos mais intelectualizados.

As comemorações dos trezentos anos da morte de Luís de Camões iriam encontrar também no Brasil excelente acolhida, revelando-se um momento notável das relações culturais entre Portugal e Brasil naquele momento.

Um pitoresco relato da repercussão das comemorações no Rio de Janeiro, publicado pouco mais de uma semana após os festejos, pode ser lido na Revista Ilustrada de 19 de junho de 1880, na coluna "Crônicas Fluminenses", assinada com o pseudônimo de July D. O mesmo suplemento vinha ainda recheado com diversas ilustrações de Camões e das comemorações. E era assim que o cronista iniciava a sua síntese dos eventos:

Esta semana não teve história própria: foi consagrada ao ócio e ao descanso, e o pouco que viveu, viveu-o da vida festiva da outra, como verdadeira parasita que foi. Cada um achou-se cansado de tanta festa, e guardou o seu entusiasmo e a sua casaca, para ficar em casa e resmoer o centenário de Camões, a estirar-se, lendo os suplementos comemorativos das folhas diárias, bocejando e finalmente dormindo (...)

Nós temos o fôlego mais curto do que o fôlego do Criador: Deus só descansou depois de uma semana de trabalho; nós espreguiçamo-nos, estremunhados, ao quarto dia de festejos e de entusiasmo. E, eu confesso, nunca vi tanta resistência, tanta atividade, nem tamanha sede de festas, no Rio de Janeiro, em homenagem a um homem que nem sequer nos pode agradecer. Os poetas debulharam-se em alexandrinos, o comércio em luzes, o povo em contentamento. Desde o dia 8 , já não havia luvas nem 
rimas no mercado: oferecia-se um conto de réis por um camarote no Pedro II, e dez contos por uma rima para espírito... ${ }^{6}$

Pelas palavras do cronista, foi grande o envolvimento da população da capital brasileira. Intelectuais, comerciantes e o povo em geral prestaram de alguma forma sua homenagem ao poeta.

O Real Gabinete Português de Leitura do Rio de Janeiro, apoiado pela comunidade portuguesa, seria responsável por alguns dos principais episódios vinculados àquela data festiva.

No mesmo dia 10 de junho de 1880 , colocou-se a pedra fundamental do que viria a ser a sede definitiva da instituição. Barros Martins, em estudo pioneiro dedicado à história do Gabinete, faz um bom relato do acontecimento:

No memorável dia 10 de junho de 1880 , decorridos trezentos anos depois da morte do glorioso Épico, e quando, a população desta Capital festejava ruidosamente este notável acontecimento, na antiga rua da Lampadosa hoje Luís de Camões, era lançada a pedra fundamental do belo templo.

A este grande ato compareceram o Imperador, ministros, homens notáveis nas letras, ciências e artes, a Câmara Municipal que se apresentou solene, com o respectivo estandarte, caso raro, (visto que se tratava de um edifício particular) o que deu ao ato extraordinária importância, muitas pessoas gradas, associações brasileiras e portuguesas, representadas pelas respectivas diretorias, e uma grande massa popular que contemplava o majestoso e comovente espetáculo. ${ }^{7}$

Mais à noite, também por iniciativa do Gabinete Português de Leitura, realizou-se, no teatro Pedro II, sessão solene dedicada ao vate português, a que estiveram presentes o imperador e a imperatriz Teresa Cristina. Diversos escritores e artistas importantes da capital brasileira colaboraram no evento. Machado de

6 REVISTA ILUSTRADA. Rio de Janeiro, n. 212, 19 jun. 1880.

7 MARTINS, A. A. de B. Esboço histórico do Gabinete Português de Leitura no Rio de Janeiro. Rio de Janeiro: Tip. do Jornal do Comércio, 1901. p. 50-51. 
Assis viu sua peça Tu, só tu, puro amor..., redigida por encomenda do Gabinete, encenada pela companhia do ator português Furtado Coelho, que representou, ele mesmo, o papel de Luís de Camões. Além da récita de muitos poemas endereçados ao poeta português, ouviu-se ainda discurso proferido por Joaquim Nabuco e hinos compostos pelos músicos Carlos Gomes, Artur Napoleão e Leopoldo Miguez. ${ }^{8}$

Mas as celebrações não se restringiram àqueles eventos capitaneados pelo Gabinete e concentrados no teatro Pedro II. Outros eventos ocuparam algumas das principais instituições sociais e culturais da cidade. Os principais órgãos da imprensa do Rio de Janeiro, como o Jornal do Comércio, a Gazeta de Notícias e A Estação, fizeram circular suplementos especiais dedicados ao poeta, com a colaboração de alguns dos mais prestigiados intelectuais da capital.

A Revista Brasileira, na qual Machado de Assis vinha publicando suas Memórias póstumas de Brás Cubas, fez também circular extenso suplemento, anexo a seu quarto número, intitulado "Homenagem a Luís de Camões - 10 de junho de 1880", com a presença de poemas de 49 prestigiados colaboradores, entre eles o mesmo Machado. ${ }^{9}$

Numa das notas de apresentação ao suplemento, lê-se texto do Imperador Pedro II:

Representante da Nação Brasileira, e amigo das letras e de seus cultores, não hesito em anuir ao pedido de colocar o meu nome entre os dos meus patrícios, que, na grinalda de versos consagrada a Camões, o maior gênio da língua falada por dois povos irmãos,

8 MAGAlHÃES JÚNIOR, R. Vida e obra de Machado de Assis. Rio de Janeiro: Civilização Brasileira, 1981. v. 3, p. 4-5.

9 Além da peça Tu, só tu, puro amor..., Machado de Assis redigiu ao todo quatro sonetos dedicados a Luís de Camões saídos em diferentes periódicos por ocasião do tricentenário, enfeixados posteriormente sob o título "Camões" e publicados em Ocidentais (Poesia completa, 1901). O volume Coleção camoniana, de José do Canto (Lisboa: Imprensa Nacional, 1895), detalhada bibliografia do poeta português e do que sobre ele se escreveu até aquela data, indica ainda um quinto soneto escrito por Machado, com os versos iniciais "Ninguém alçou mais numeroso canto; / Ninguém mais vasta possuiu a lira", e que teria sido publicado no "Suplemento Ilustrado" da Revista Ilustrada do dia 10 de junho de 1880, no Rio de Janeiro. Em pesquisa na Biblioteca Nacional, não logrei localizar o referido suplemento. Vale sublinhar que nem Galante de Sousa (Bibliografia de Machado de Assis), nem R. Magalhães Jr. (Vida e obra de Machado de Assis), nem Gilberto Mendonça Teles (Camões e a poesia brasileira) referem-se à existência do poema. 
cantor das maravilhas da navegação, a que devemos o nosso Brasil, conseguiram simbolizar os mais generosos sentimentos, imitando a exuberância viçosa e bela de um solo, cujas admiradas riquezas oferecemos cordialmente ao espírito industrioso de todas as outras nações.

Estas palavras, escritas ao correr da pena, cingirão a formosa grinalda, ao menos, como laço de simpatia.

D. PEDRO II $^{10}$

Aí está, em síntese, a justificativa oficial para as comemorações brasileiras. Camões, "o maior gênio da língua falada por dois povos irmãos", é o "cantor das maravilhas da navegação", fato histórico que estaria na gênese do próprio Brasil. Enfatiza-se a fraternidade luso-brasileira (com destaque para os vínculos lingüísticos) e uma continuidade histórico-cultural que permitiria reivindicar para o Brasil a figura de Luís de Camões como um patrono recuado (mesmo que involuntário) também da nacionalidade brasileira.

As comemorações camonianas teriam igualmente lugar em outras províncias, de norte a sul do Império. Diversos estudos de maior fôlego, publicados em livro, sairiam também naquele e nos anos seguintes. ${ }^{11}$

Fugindo um pouco ao âmbito dos eventos de intenção mais marcadamente intelectual, vale a pena acompanhar a irradiação dos festejos para outras órbitas. O mesmo cronista da Revista Ilustrada do dia 19 de junho, mais atrás convocado, depois de arrolar alguns dos principais fatos do dia, arrematava:

(concluiu-se) tudo no domingo com as regatas em Botafogo, a festa marítima mais esplêndida, mais deslumbrante que o Rio de Janeiro tem visto - um luxo, uma vaidade, uma orgia de luz e de adornos. O povo aliou-se ao Club das regatas, enfeitando todas as sacadas, iluminando os jardins; e à noite, as gôndolas venezianas,

10 REVISTA BRASILEIRA. Rio de Janeiro: Tipografia Nacional, v. 4, p. 357, 1880. O mesmo suplemento comemorativo encontra-se integralmente reproduzido em: MONTORO, R. C. O centenário de Camões no Brasil - Portugal em 1580 - o Brasil em 1880. 2. ed. Rio de Janeiro: Antônio José Gomes Brandão, 1880.

11 Informações mais detalhadas sobre este e outros tópicos tratados na presente comunicação fazem parte do primeiro capítulo de minha tese de doutorado, intitulada Aquémalém-mar: presenças portuguesas em Machado de Assis, em fase final de redação (Doutorado em Teoria Literária, IEL, Unicamp). 
o fogo de artifício (...) a baía de Botafogo parecia um cenário imenso de peça fantástica. ${ }^{12}$

Confiando-se nas palavras do cronista, percebe-se que as comemorações acabariam por extrapolar o âmbito mais restrito dos edifícios e a percorrer também as ruas, chegando inclusive ao mar.

A propósito, folheando-se as páginas da Gazeta de Notícias do mesmo dia 10 de junho dedicadas aos reclames, percebe-se o quanto o nome de Camões escapou do mundo das letras e veio inscrever-se, por exemplo, junto ao comércio. São diversas as chamadas que tomam o tricentenário como mote. Pelo sabor e pela curiosidade, vale a pena acompanhar aqui algumas delas.

Com grande destaque ao alto da página 8, lê-se, em duas linhas: "Terceiro Centenário de Camões / Lembrança útil, duradoura e vantajosíssima". Abaixo da manchete, o seguinte texto:

O nosso chefe, amador das letras, das artes e das ciências, não quer deixar passar esta ocasião secular sem festejar de uma maneira útil o aniversário deste grande vulto literário português. Por conseqüência, deu-nos ordem para tirar da reserva dos cofres quantidade de relógios especiais de prata e prata dourada, excelentes, meio-patentes de primeira qualidade, e que desafiam qualquer competência (...). Acha-se gravado, sobre o guarda pó dos ditos relógios, além do título verdadeiro de regulador:

\section{TERCEIRO CENTENÁRIO DE CAMÕES 10 DE JUNHO DE 1880}

Estes relógios, bons, bonitos e modernos, de se dar corda e acertar pela coroa, podem servir: $1{ }^{\circ}$ Às pessoas que já têm um relógio de preço ou de estima para substituí-lo em viagem ou no trabalho. $2{ }^{\circ}$ A qualquer patrão que quiser deixar uma lembrança deste dia grande por mais de trinta anos a um bom empregado. $3 .^{\circ}$ Às pessoas que precisam de um bom regulador, e que não podem

12 REVISTA ILUSTRADA. Rio de Janeiro, n. 212, 19 jun. 1880. 
gastar muito, APOSENTANDO assim toda a cangalha em relógios que tiverem comprado até agora.

Promoção durante os dias 10, 11, 12 e 13 de junho.

Assinam - Os empregados da Relojoaria E. J. Gondolo - Rua da Candelária $n .^{\circ} 16 .{ }^{13}$

Na mesma página do periódico, podia-se ainda ler: "Grand Restaurant Oliveira - Rua Uruguaiana n. ${ }^{\circ} 29$ / Almoços a 800 rs.; jantares a 1\$000. O proprietário deste importante estabelecimento tem a honra de apresentar hoje um prato especial a seus amigos e fregueses, intitulado / À CAMÕES.”

São diversos os anúncios que apelam ao nome do poeta português, indo desde as lojas de moda, muito freqüentes, até os restaurantes.

Como se pode ver, as comemorações do tricentenário de Camões no Brasil, assim como havia ocorrido em Portugal, transbordaram os limites mais fechados dos círculos literários. Do Imperador D. Pedro II aos empregados da Relojoaria E. J. Gondolo, da peça teatral de Machado de Assis e do discurso de Joaquim Nabuco ao prato do dia do Grand Restaurant Oliveira, o nome do poeta circulou amplamente, numa explícita demonstração de sua popularidade entre nós.

\section{RESUMO}

O presente artigo trata das comemorações do tricentenário de Luís de Camões no Brasil em 1880 e de sua repercussão na imprensa do Rio de Janeiro.

Palavras-chave: Luís de Camões, Literatura Comparada Portuguesa e Brasileira, Literatura e Sociedade.

13 GAZETA DE NOTÍCIAS. Rio de Janeiro, 10 jun. 1880. 


\begin{abstract}
This paper deals with the celebration of Luís de Camões' third centennial in Brazil and with it's repercussion in the press of Rio de Janeiro.

Key-words: Luís de Camões, Portuguese and Brazilian Contrastive Literature, Literature and Society.
\end{abstract}

\title{
REFERÊNCIAS
}

ASSIS, M. de. Obra completa. Rio de Janeiro: Nova Aguilar, 1997. v. 3, 9. ${ }^{\text {a }}$ reimpressão.

CABRAL, A. Comemorações Camonianas de 1880. In: Notas oitocentistas - I. Lisboa: Horizonte, 1980.

CANTO, J. do. Coleção camoniana. Lisboa: Imprensa Nacional, 1895.

GAZETA DE NOTÍCIAS. Rio de Janeiro, 10 jun. 1880.

MAGALHÃES JUNIOR, R. Vida e obra de Machado de Assis. Rio de Janeiro: Civilização Brasileira, 1981. v. 3.

MARTINS, A. A. de B. Esboço histórico do Gabinete Português de Leitura no Rio de Janeiro. Rio de Janeiro: Tip. do Jornal do Comércio, 1901.

NABUCO, J. Camões. Discurso pronunciado a 10 de junho de 1880 por parte do Gabinete Português de Leitura. Rio de Janeiro: Biblioteca Nacional, 1980. Edição facsimilada.

REVISTA BRASILEIRA. Rio de Janeiro: Tipografia Nacional, v. 4, 1880.

REVISTA ILUSTRADA. Rio de Janeiro, n. 212, 19 jun. 1880.

SOUSA, J. G. de. Bibliografia de Machado de Assis. Rio de Janeiro: INL, 1955.

TELES, G. M. Camões e a poesia brasileira. 3. ed. rev. Rio de Janeiro: Livros Técnicos e Científicos, 1979. 